\title{
CHINA Y SU IMPACTO EN LA INTEGRACIÓN COMERCIAL DE LA ASOCIACIÓN DE NACIONES DEL SUDESTE ASIÁTICO (ASEAN)*
}

\section{CHINA: IMPACT ON TRADE INTEGRATION OF ASEAN}

\author{
José Andrés Díaz González** \\ Orlando Vega Quesada***
}

\section{RESUMEN:}

El presente artículo analiza el proceso de integración comercial de los países miembros de la Asociación de Naciones del Sudeste Asiático (ASEAN). Si bien la integración política de estos países está bastante consolidada, una revisión de distintos indicadores económicos y comerciales muestra una débil integración comercial. Al observar el efecto de la política comercial de China en Asia, se constata que este ayuda a fortalecer la integración comercial de la ASEAN; sin embargo, no lo hace en suficiente medida para poder considerar que existe una integración completa en este aspecto.

Palabras claves: China, Asia, comercio internacional, integración, política comercial, ASEAN

\begin{abstract}
ABSTRAC:
This article analyzes the process of trade integration of the member countries of Association of Southeast Asian Nations (ASEAN). Although the political integration of these countries is well established, a review of different economic and trade indicators show a weak trade integration. By observing the effect of China's trade policy in Asia, it is found that this helps strengthen trade integration of ASEAN; however, does not sufficiently for there to be a complete integration in this regard.
\end{abstract}

Keywords: China, Asia, International Trade, Integration, Trade Policy, ASEAN

* Los autores desean agradecer los comentarios realizadas por el Dr. Abelardo Morales a una versión preliminar del presente texto, así como a la persona evaluadora del artículo por sus observaciones y sugerencias. No obstante, cualquier error u omisión presentes en el artículo es de responsabilidad exclusiva de los autores.

** Docente. Escuela de Ciencias Políticas, Universidad de Costa Rica. Correo electrónico: joseandres. diaz@ucr.ac.cr

***Estudiante del Doctorado en Gobierno y Políticas Públicas (UCR), Magíster en Población y salud, Licenciado en Ciencias Políticas. Escuela de Ciencias Políticas, Universidad de Costa Rica. Correo electrónico: orlando.vega@ucr.ac.cr 


\section{Introducción}

Los procesos de integración regional pueden encontrarse influenciados por varios factores, por ejemplo, según la teoría de la localización -desarrollada por Alfred Weber- elementos como las economías externas, recursos naturales y posibilidades de trasporte se pueden identificar como determinantes para el desarrollo de una región (Balassa, 1980). En ese sentido, se pretende, en este documento, visualizar los elementos que han conllevado a los países del sudeste asiático a la conformación de la Asociación de Naciones del Sudeste Asiático (ASEAN, por sus siglas en inglés) en búsqueda del fomento de la integración, a luz de los diversos aportes teóricos.

Asimismo, siguiendo a Sargant Florence, al considerar el papel que pueden jugar las economías de yuxtaposición en la conformación de las regiones, se explora el papel que ha tenido la República Popular de China (RPC) sobre la región del Sudeste Asiático y la interacción económica a partir de las reformas realizadas en ese país en las últimas décadas, así como la integración de la ASEAN dentro de su estrategia económica, producto del acercamiento que tienen ambos actores en los últimos años, que se materializa con la entrada en vigencia del Tratado de Libre Comercio a partir del año 2005 con las primeras disminuciones arancelarias (EFE, 2010).

Adicionalmente, un elemento que se debe considerar dentro de este contexto se encuentra en torno al uso del mar meridional de China, ya que para el año 2002 se da la Declaración sobre las conductas de los países en dicho espacio geográfico, por parte de la ASEAN y RPC; no obstante, debido a múltiples diferencias de posiciones por parte de los países, no es hasta nueve años después, cuando se aprueban las directrices de implementación, las cuales son ratificadas en la Décima Octava Cumbre de la ASEAN y RPC. Esta garantiza:

a) Construir, mantener y mejorar la confianza mutua;

b) Actuar con moderación en la realización de las actividades;

c) No recurrir a la amenaza o al uso de la fuerza;

d) Para los Estados soberanos directamente interesados resolver sus diferencias y disputas por medios pacíficos, incluso a través de consultas amistosas y negociaciones, de conformidad con el derecho internacional, incluyendo Convenciones de las Naciones Unidas sobre el Derecho del Mar (UNCLOS, por sus siglas en inglés) de 1982. (ASEAN, 2016 , párr.7-10) 
Teniendo presente dichos elementos, este documento se da a la tarea de identificar, en primer lugar, los principales aportes teóricos en torno a la creación de regiones; seguidamente se analiza, para el caso del Sudeste Asiático, el impacto de la constitución del ASEAN para su regionalización. Asimismo, se describen las principales reformas económicas presentadas en la RPC en los últimos años, las cuales han facilitado la integración, principalmente económica, con el fin de determinar qué ha tenido más peso para la formación de la región: los factores internos (ASEAN) o los externos (RPC).

Los acercamientos para dar respuesta a estas interrogantes se desarrollan a partir de la información disponible en investigaciones previas de la región, informes y periódicos de la ASEAN, datos del Banco Mundial y estadísticas de la oficina nacional de estadísticas de la RPC. Utilizar datos provenientes de fuentes secundarias es una limitación del presente artículo, ya que estos no necesariamente fueron generados para tratar de dar respuestas a las interrogantes que se han planteado. Sin embargo, se trata de superar esta limitación contrastando estos datos con lo dispuesto por diversa bibliografía académica que trata el caso de la integración de la ASEAN.

\section{Un acercamiento teórico al estudio de las regiones}

Los estudios sobre las regiones y, más específicamente, de los procesos de regionalización y de la integración de estas -o su construcción- han tomado una particular importancia en las últimas décadas. Así, a partir de mediados de la década de 1980 empiezan a emerger los estudios enfocados en el "nuevo regionalismo"; el cual, según Hettne y Söderbaum (2000), es promovido por los intentos de comprensión de los cambios que estaban ocurriendo en la estructura del sistema mundial. Estos cambios en el sistema mundial se encuentran relacionados con:

1. Cambio de un sistema bipolar a uno multipolar o, tal vez, tripolar

2. El relativo debacle de la hegemonía estadounidense

3. La consolidación del proceso de globalización y el aumento de la interdependencia entre los países

4. La adopción de reformas económicas neoliberales, tanto por los países en desarrollo como por las naciones "post-comunistas". (Hettne y Söderbaum, 2000, p. 544) 
En esa línea es necesario, previamente, distinguir conceptos que por su similitud suelen ser confundidos, pero que denotan dos procesos distintos. El primero, es la integración regional, también denominado como regionalismo, el cual denota un proceso formalizado y conducido desde los Estados. El segundo es el concepto de regionalización, el cual sirve para nombrar un proceso (que puede ser) informal, por el cual se incrementan los flujos de intercambio entre una serie de países que se encuentran territorialmente contiguos. Así, si bien los procesos de regionalización pueden servir como base para el posterior desarrollo de un proyecto de integración regional, es necesario tomar en consideración que el actor principal en su promoción no es el Estado, sino el mercado o los grupos de la sociedad civil (Malamud, 2011).

Tomando lo anterior en consideración, en el presente documento lo que se visualiza es un proceso de integración regional o regionalismo ya que, como se expone más adelante, son los Estados (representados tanto en los gobiernos de la ASEAN como de la RPC), los que, de forma consiente, impulsan el desarrollo de la región. Llegado a este punto, el primer paso es el definir qué se entenderá por región; sin embargo, esta no es una tarea sencilla, ya que este es un concepto polisémico, el cual es utilizado para hacer algún tipo de referencia a las interacciones espaciales, geográficas, jurídicas, económicas, sociales, políticas o culturales que acontecen en un territorio determinado, lo que lleva a que las personas estudiosas del tema no hayan podido llegar a un acuerdo mínimo sobre el concepto (Van Langenhove).

A la complejidad del tema, debe agregarse que existen regiones tanto a nivel supranacional como subnacional; definido este último como la cooperación transnacional desarrollada entre entidades subestatales (provincias o comunidades autonómicas), y que suelen estar vinculados con fenómenos sociales, culturales (como las comunidades lingüísticas separadas por fronteras estatales) y políticos (como la paradiplomacia o relaciones internacionales desarrolladas por gobiernos subnacionales) (Malamud, 2011). A pesar de esto, queda claro que el interés del presente texto se centra en las regiones a nivel supranacional, por lo que se adopta la siguiente definición de región:

Cualquier área geográfica que abarque dos o más Estados Nacionales o partes de éstos (contiguas o no) que, a partir del incremento de los contactos e intercambios internacionales y transnacionales a su interior, comienza a transformarse de un objeto pasivo en un sujeto activo, capaz de articular los intereses de sus ciudadanos por diferentes vías, ya sea a través de los propios Estados o mediante la formación de una sociedad civil regional. (Alzugaray Treto, 2009, p. 10) 
En cuanto al proceso de integración regional, este puede desarrollarse de manera positiva o negativa. Los procesos negativos hacen referencia al desmantelamiento de restricciones a los intercambios fronterizos y a la distorsión de la competencia; mientras tanto, la integración positiva refiera a la adopción de políticas comunes que moldeen el funcionamiento de los mercados (Malamud, 2011).

La anterior distinción es importante, ya que la integración negativa puede alcanzarse mediante la implementación de medidas intergubernamentales, mientras que la integración positiva solo puede lograrse con la construcción de organizaciones supranacionales (Malamud, 2011).

Con lo expuesto en este apartado, se pasará a revisar el proceso ocurrido entre ASEAN y RPC, para determinar si este lleva a la consolidación de una región en el sudeste asiático, y si esta presenta características de un proceso de regionalización positiva o negativa.

\section{La ASEAN como instrumento de integración regional}

La ASEAN es una organización regional de Estados del sudeste asiático cuyo principal propósito es promover el desarrollo económico de la región y trabajar en conjunto por la promoción de la paz y la estabilidad política de sus países miembros. Esta organización fue constituida el 8 de agosto de 1967, por cinco países: Indonesia, Malasia, Filipinas, Singapur y Tailandia. El 8 de enero de 1984 se unió Brunei Darassalam, el 28 de julio de 1995 se unió Vietnam, el 23 de julio de 1997 se unieron Laos y Birmania y el 30 de abril de 1999 se unió Camboya (Guerrero y Mendieta, 2013).

La ASEAN surge durante la Guerra Fría, en medio de la guerra de Vietnam; eso explica que su creación fuera motivada por los Estados Unidos, como parte de una estrategia para tratar de detener los avances del comunismo en Asia. De esta manera, la organización nace como un foro regional de cooperación para promover el reparto de la ayuda estadounidense; es decir, las razones geopolíticas dominan a las económicas en la interpretación del surgimiento de este bloque asiático (Guerrero y Mendieta, 2013; Plaza Cerezo, 1995).

Dada esta situación, algunos estudios han planteado que la ASEAN no ha sido muy exitosa en el plano de la integración económica; indican, además, que para la década de 1990, su mayor logro en esta materia había sido la firma del Acuerdo de Preferencias Comerciales Recíprocas (PTA, por sus siglas en 
inglés), el cual se orientaba al fomento de la expansión del comercio intrarregional mediante la concesión de preferencias comerciales sobre la base de una negociación producto por producto (Plaza Cerezo, 1995).

En su intento de convertirse en una comunidad de Estados consolidada, la cual sirva como base para el desarrollo de sus miembros en diferentes ámbitos, los países integrantes de la ASEAN han adoptado, al 2015, un total 82 distintos acuerdos, en los cuales sobresale que 59 de ellos pertenecen al área económica (ASEAN, 2016c); uno de los más importantes es el Tratado de Amistad y Cooperación de la Asociación (TACSE), el cual fue firmado en 1976, con el propósito de establecer como principales objetivos de esta organización:

- Respeto mutuo por la independencia, soberanía, igualdad, integridad territorial e identidad nacional de todos los miembros.

- El derecho de cada estado a guiar su existencia nacional libre de cualquier coerción, interferencia o subversión exterior.

- No-interferencia en los asuntos internos de otro país.

- Solución de las diferencias o disputas por medios pacíficos.

- Renuncia a la amenaza o uso de la fuerza.

- Cooperación efectiva entre los países miembros. (Guerrero y Mendieta, 2013, p. 18)

No obstante, el acuerdo más importante adoptado por los miembros de la ASEAN ha sido la conformación del Área de Libre Comercio del Sudeste Asiático (AFTA, por sus siglas en inglés) en 1992; sin embargo, este no entró en vigor sino hasta 10 años después, el 1 de enero del 2002. Al respecto, Rubiolo (2006) visualiza la firma de este acuerdo comercial como un reconocimiento de los países del ASEAN de la existencia de una interdependencia entre ellos, la cual era necesaria consolidar y facilitar para poder alcanzar un mayor desarrollo económico:

La interdependencia es esencial tanto en el proceso de construcción de una identidad colectiva, como en el de cooperación regional. Tiene su fundamentación en la confianza entre las partes, dado que no habrá relación de interdependencia duradera sin ella. El Acuerdo para el establecimiento del Área de Libre Comercio de la ASEAN, se basa en el convencimiento de que existe una genuina relación de interdependencia entre los miembros, que ante la 
eliminación de barreras al comercio favorecerá el crecimiento de cada una de las economías en cuanto crecen las de los vecinos. Del mismo modo, un deterioro en las condiciones económicas de uno de los Estados podría perjudicar a los restantes mercados, en tanto se interrumpiría el flujo comercial y de capital entre ellos. La interdependencia es el concepto sin el cual no podría, en primera instancia, comenzarse un proceso de cooperación. (Rubiolo, 2006, p.18)

Tomando lo anterior en consideración, es necesario cuestionar si la firma del AFTA, así como la existencia general de la ASEAN, ha traído mejores condiciones para el desarrollo económico de sus miembros. Si bien es cierto que hay distintos factores y características individuales que intervienen al momento de determinar el desarrollo económico de un país, de existir un proceso de integración tan fuerte como el mencionado por Rubiolo (2006), sería esperable observar algún tipo de patrón o tendencia general común en los indicadores económicos de los países miembros de la ASEAN.

La figura 1 muestra el ingreso, de países miembros de la ASEAN, en dólares constantes del 2005. A primera vista se puede indicar que, en general, durante este periodo el ingreso per cápita de los miembros de la ASEAN crece de manera constante, el cual se ve incrementado a partir del año 2005, año en que se inicia la entrada en vigencia de las primeras disminuciones arancelarias producto del Tratado de Libre Comercio con China. Sin embargo, se debe indicar que también hay importantes diferencias respecto al monto y ritmo de crecimiento: el caso más llamativo es el de Malasia, ya que no solamente es el país que reporta los mayores ingresos per cápita en todo el periodo, sino que también, prácticamente, quintuplica el ingreso de sus habitantes en un lapso de 40 años, pasando de un ingreso promedio de unos \$1174 en 1970, a \$5682 en el 2013.

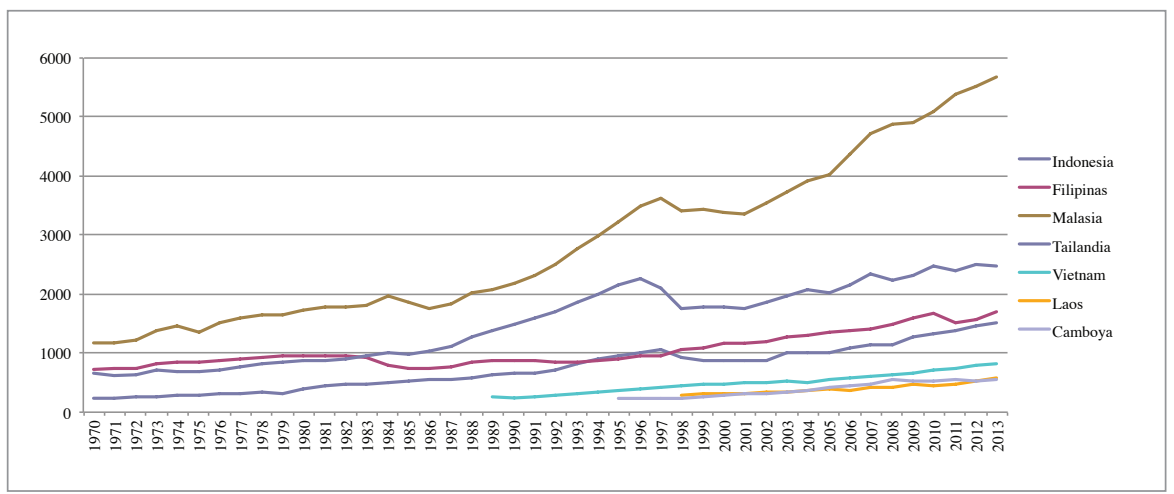

Figura 1. Ingreso per cápita de los países de la ASEAN, 1970-2013 -en dólares constantes del 2005-. *No se incluyen datos de Brunéi y Singapur, ya que no se encuentran disponibles. Elaboración propia, a partir de datos del Banco Mundial. 
Sin embargo, a pesar de tener esta tendencia general común del aumento en sus ingresos per cápita, las diferencias existentes entre los países miembros de la ASEAN son notables. Así, mientras que, para el 2013, los ingresos per cápita en Malasia se acercan a los $\$ 6000$, el resto de los países miembros de esta organización tuvo ingresos per cápita por debajo de los $\$ 2500$, incluso, los ingresos promedio de la población de Camboya estaban por debajo de los $\$ 550$.

Esas diferencias en los ingresos también permiten encontrar diversas disparidades en varios indicadores económicos, por ejemplo, al considerar las tasas de desempleo (figura 2). Para el año 2014 existen diferencias superiores al 1625\% entre la tasa de desempleo que reporta Camboya (el de menor registro) con el de Filipinas (el de mayor registro). En ese sentido se debe recalcar el hecho de que Camboya es el país de la región de la ASEAN con el menor ingreso per cápita y con la menor tasa de desempleo de la región. Otro elemento importante a destacar es que los países no reportan grandes cambios durante el periodo de análisis en sus tasas de desempleo, prácticamente con una estabilidad en este mismo con valores inferiores al 4\%; sin embargo, para los casos de Filipinas e Indonesia, los cuales reportan las mayores tasas de desempleo, si bien logran disminuirlo a partir del año 2003 y 2005 respectivamente, siguen manteniendo las tasas más altas de la región (superiores al 7\%).

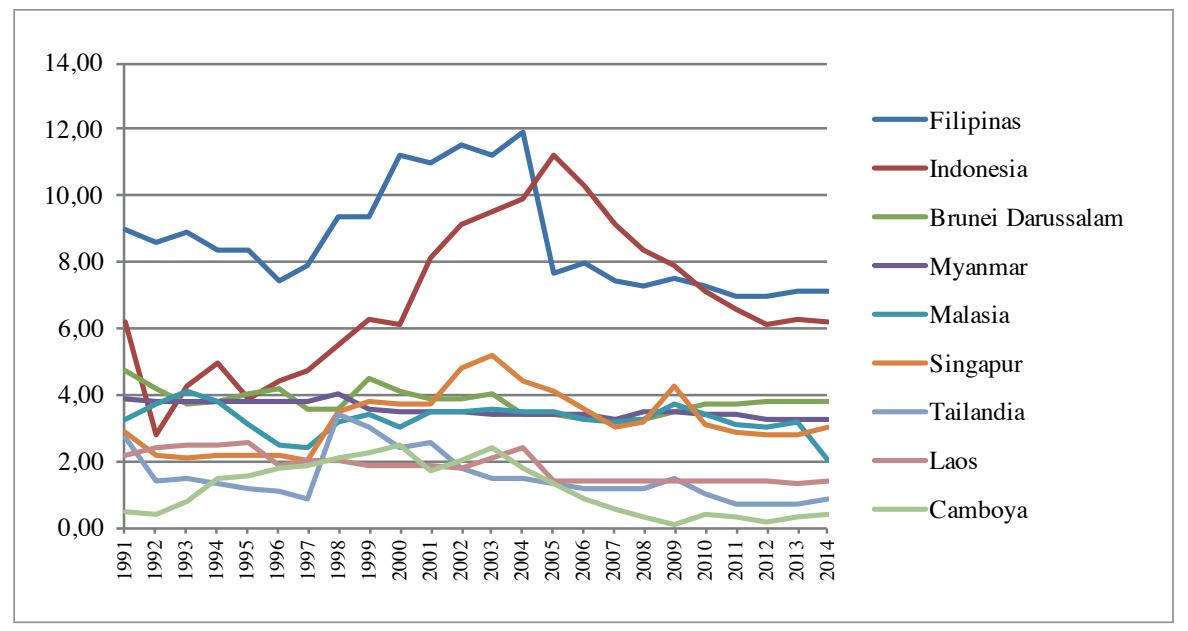

Figura 2. Tasa de desempleo países de la ASEAN, 1991-2014. Elaboración propia a partir de datos del Banco Mundial.

Además, tampoco se aprecia que la entrada de vigencia del AFTA, en el 2002, haya tenido un impacto sustantivo en el ingreso per cápita de la población (figura 3), ya que no se observan cambios sustanciales en la tendencia de 
este indicador después de la entrada en vigencia de dicho tratado. Se debe destacar que los cambios negativos presentes en la gráfica son consecuentes con la crisis del petróleo presentada a finales de los años setenta e inicios de los años ochenta y la crisis asiática a finales de años noventas (Hernández, 2008). Asimismo, la variación negativa de Filipinas en la década de los ochentas es consecuente a la crisis política que vivía dicho país (Vilaro, 2005).

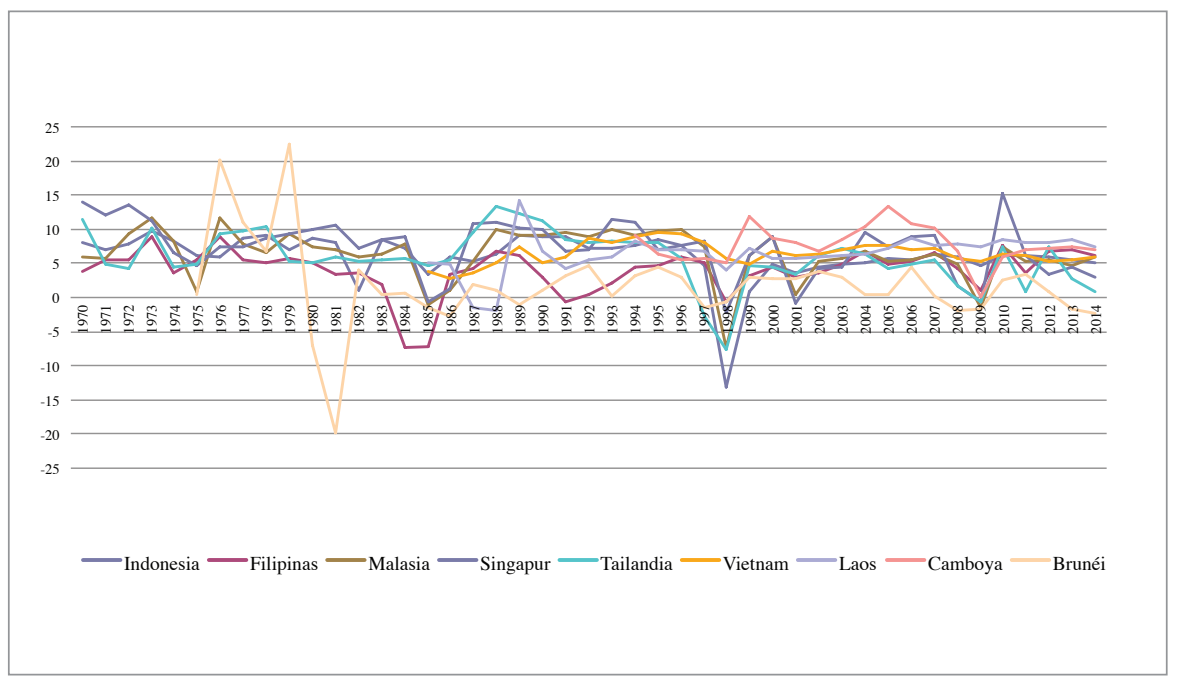

Figura 3. Porcentaje de variación del PIB de los países de la ASEAN, 1970-2014. Elaboración propia, a partir de datos del Banco Mundial.

Al observar el comportamiento de la variación del PIB de los países miembros de la ASEAN se puede constatar que este no parece seguir ningún tipo de patrón, o tendencia general común, salvo por lo sucedido en 1998 por la crisis asiática; año en el que el PIB de todos los países de la región disminuye al unísono, pero en porcentajes muy diferentes.

También llama la atención que no existe una relación entre la variación del PIB y el ingreso per cápita en los países miembros de la ASEAN (tabla 1); en otras palabras, la producción realizada en dichas naciones parece que no está siendo el factor determinante para explicar los cambios en el ingreso promedio de sus habitantes; con la salvedad del caso de Laos, donde sí se encuentra una correlación medianamente fuerte entre ambas variables, sin embargo, esta solo puede explicar un $60 \%$ de los casos. 
Tabla 1

Correlación entre la variación del PIB y el ingreso per cápita de los países miembros de la ASEAN, (1970-2014)

\begin{tabular}{|l|c|c|}
\hline & Correlación & $\mathbf{R 2}$ \\
\hline Vietnam & $\mathbf{- 0 , 4 6}$ & $\mathbf{0 , 2 0}$ \\
\hline Tailandia & $\mathbf{- 0 , 3 3}$ & $\mathbf{0 , 1 1}$ \\
\hline Malasia & $\mathbf{- 0 , 2 4}$ & $\mathbf{0 , 0 6}$ \\
\hline Laos & $\mathbf{0 , 7 7}$ & $\mathbf{0 , 5 9}$ \\
\hline Indonesia & $\mathbf{- 0 , 2 7}$ & $\mathbf{0 , 0 7}$ \\
\hline Filipinas & $\mathbf{0 , 2 5}$ & $\mathbf{0 , 0 6}$ \\
\hline Camboya & $\mathbf{- 0 , 0 7}$ & $\mathbf{0 , 0 1}$ \\
\hline
\end{tabular}

Nota: Construcción propia, a partir de datos del Banco Mundial.

En materia de distribución del ingreso al considerarse el índice de Gini de los países del ASEAN, para el periodo de 1981 al 2012 (figura 4), se nota cómo la desigualdad se ha ido incrementado, con únicamente dos excepciones: Camboya (2007) y Tailandia (2006). Asimismo se debe señalar que Malasia es el país de la ASEAN con mayor ingreso per cápita y el que presenta el mayor nivel de desigualdad en la distribución de los ingresos. En ese sentido, vale la pena destacar el hecho de que, además de las diferencias expuestas hasta este momento entre los países, se están presentando diferencias a los interno de ellos en materia de la distribución de los ingresos, elemento que podría influir en contra de los procesos de integración, debido a la generación de ese tipo de inequidades a lo interno de los países, lo cual podría llegar a ser entendido por diferentes actores locales, como consecuencia de los modelos económicos promovidos desde los diferentes acuerdos establecidos en el seno de la ASEAN. 


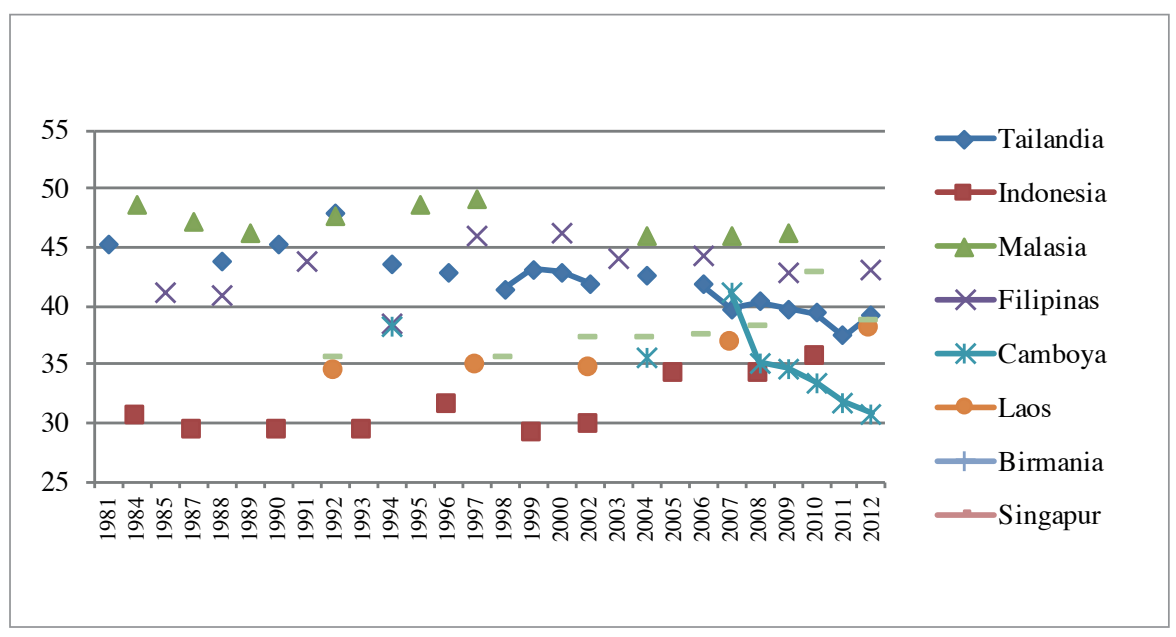

Figura 4. Índice de Gini, Países de ASEAN (a), 1981-2012 (b). No se incluye a Brunei, ya que no se cuentan con datos para la serie de años representados. Se excluye el año 1982, 1983, 1986 y 2011 ya para esos años no se registra ningún dato para los países incorporados en el gráfico. Elaboración propia con datos del Banco Mundial.

Otro elemento asociado a la desigualdad es el dato del sector que vive con menos de $\$ 1.90$ por día, el cual permite medir la población en condición de pobreza. Respecto a esto, existe una disminución significativa para los países de la región del Sudeste Asiático, ya que datos del Banco Mundial indican que para el año 1990 el 50,6\% de la población de la región del Sudeste Asiático vivía en esa condición, y esta cifra se disminuyó en el 2012 a 18,8\% (Banco Mundial, 2014). En la figura 5 se puede observar que se destacan las disminuciones de Indonesia y Camboya, las cuales han logrado mermar en más de tres cuartas partes a la población en esa condición. 


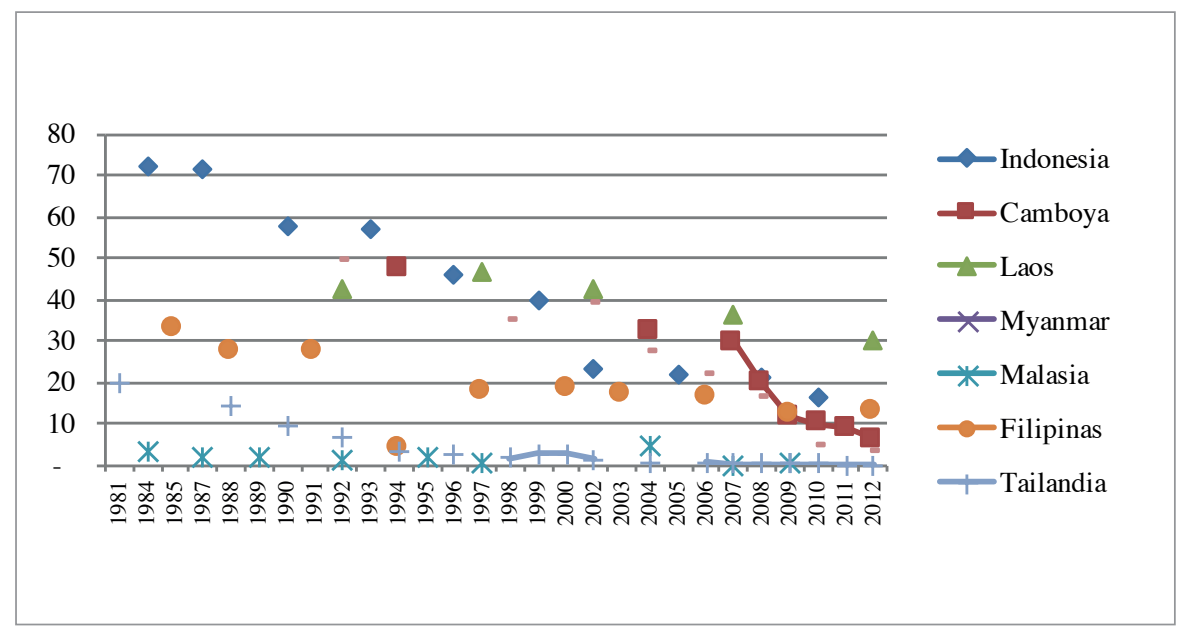

Figura 5. Tasa de incidencia de la pobreza, sobre la base de $\$ 1,90$ por día (2011 PPA) en países de la ASEAN (a), 1981-2012. No se incluye a Brunei, ya que no se cuentan con datos para la serie de años representados. Se excluye el año 1982, 1983, 1986 y 2011 ya para esos años no se registra ningún dato para los países incorporados en el gráfico. Elaboración propia con datos del Banco Mundial.

\section{Política comercial China y su incidencia en la ASEAN}

La actual estrategia en política exterior de la RPC puede observarse como parte de las reformas política y, especialmente, económicas que vienen gestándose en el país desde finales de la década de 1970. De esta manera, para tener una comprensión más completa de este proceso, se pasará a realizar una breve exposición de estas reformas; las cuales inician en diciembre de 1978, impulsadas por el entonces presidente Deng Xiaoping, como un intento de alejarse de las política económicas maoístas (Wilhelmy, 2000).

Estas reformas, conocidas como la implementación del programa "Socialismo con características chinas", pueden agruparse en dos grandes periodos; el primero, llamado de Reformas iniciales (1978-1984), impulsó la descolectivización de la agricultura, promovió la incipiente apertura del país a la inversión extranjera y otorgó permisos a grupos emprendedores de iniciar empresas. El segundo periodo inicia en 1985, y se caracterizó por llevar a cabo la privatización de la industria, el levantamiento del control de precios, la eliminación de las regulaciones económicas, así como el desmantelamiento de los servicios sociales (Quiroga, 2009) 
Sin embargo, como señala Wilhelmy (2000), las reformas económicas impulsadas han chocado con la ideología comunista existente en RPC, lo que ha provocado que la élite política tenga que recurrir a mecanismos para solventar los problemas que esto genera:

Un problema central de la política de reforma es la incongruencia entre la anticuada ideología comunista - una verdadera 'letra muerta', un anacronismo, aunque conveniente $-\mathrm{y}$ las nuevas orientaciones seguidas en la práctica del ejercicio del poder, así como en la vida diaria de la población. Una vía para sortear este escollo es el nuevo énfasis en el tema de "lo chino", que tiene claras connotaciones nacionalistas y conservadoras, y que por su mismo contenido, si bien evita las viejas tesis socialistas, tiende a chocar con el estilo internacional de los procesos de apertura y liberalización. (Wilhelmy, 2000, p. 249)

Así, la consolidación del nacionalismo en RPC es importante para entender el establecimiento de su política exterior, especialmente a nivel de Asia, ya que esta iría entonces dirigida a buscar resarcir las humillaciones y agravamientos sufridos históricamente por esta nación, y a recuperar lo que considera su legítimo lugar en el orden internacional (Delage, 2003).

Asimismo, la RPC está buscando disminuir la influencia que tiene los Estados Unidos sobre Asia, no solo en procura de aumentar su influencia política para convertirse en la potencia dominante de la región, sino también como una forma de garantizar la estabilidad necesaria en la región para consolidar su proyecto de desarrollo económico. Para alcanzar este objetivo, la RPC ha desarrollado una estrategia basada en la diplomacia y en la economía (Delage, 2003). Así, se puede observar que la política exterior presenta un cambio radical, con respecto a la desarrollada anteriormente a su proceso de reforma económica:

Durante la época maoísta, la República Popular China adoptó una postura de cuestionamiento radical del sistema internacional y sus principales actores. Al no contar, sin embargo, con los medios apropiados para cambiar el statu quo de acuerdo a sus aspiraciones, esta postura revolucionaria constituyó un fracaso político, condenando a China a sufrir una prolongada situación de ostracismo internacional. Durante los últimos cinco años del régimen maoísta se produjo un importante viraje diplomático, al lograr ocupar Beijing el asiento chino en Naciones Unidas, desplazando a Taipéi e iniciando el proceso de normalización de relaciones con los Estados Unidos, que se completaría con el establecimiento de relaciones diplomáticas en 1979. (Wilhelmy, 2000, p. 266)

De esta manera, el protagonismo de RPC en Asia no ha dejado de crecer desde finales de la década de 1990. Por ejemplo, durante la crisis financiera 
de 1997-1998, la RPC no devaluó su moneda e, incluso, brindó \$4.500 millones de dólares a los paquetes de rescate del Fondo Monetario Internacional. En esa misma línea, el Gobierno chino ha impulsado la creación de un área de libre comercio con el sudeste asiático y ha apoyado los esfuerzos regionales contra el tráfico de drogas y la defensa del medio ambiente. De manera más significativa, RPC ha superado sus antiguas reservas hacia los foros multilaterales, y participó activamente en la creación de ASEAN $+3^{1}$ (Delage, 2003).

De esta manera, la creación del área de libre comercio entre la RPC y ASEAN, la cual da paso al mayor bloque comercial mundial, vendría a ser una iniciativa que responde a los intentos del Gobierno chino de hacer una transformación radical de sus relaciones con las otras naciones del área, al mismo tiempo que le permite disminuir el poder de Japón en Asia, al colocarse como el principal socio comercial del continente asiático (Delage, 2003)

A pesar de lo anterior, diversidad de analistas indican que el sistema de formulación de la política exterior china todavía parece adolecer de un déficit en términos de estrategia y de capacidad de definición del lugar de RPC en el mundo. De esta manera, consideran que existe una importante brecha entre el poder que suele pensarse que RPC tiene en el escenario internacional, y el poder que este país efectivamente ostenta en este. Lo anterior, debido a que no tiene peso comercial ni financiero global y que la mayoría de las inversiones extranjeras son hechas por grupos chinos de ultramar, o han tenido su origen en capitales originalmente procedentes de la propia RPC. No obstante estas objeciones, sí se reconoce como una potencia regional (Wilhelmy, 2000).

Por lo tanto, si bien puede haber críticas sobre la efectividad de la política exterior china para consolidar su poder a nivel global, se puede partir de la premisa de que sí ha tenido la capacidad de convertirse en una potencia en la región asiática, y que muestra un especial interés en ello para poder consolidar se modelo económico.

Las relaciones entre la RPC y ASEAN se remontan al año 1991, cuando en el marco del Vigésimo Cuarto Encuentro de Ministros del ASEAN se extiende la invitación al ministro de Relaciones Exteriores de RPC para participar como invitado especial, dando así con el inicio de una relación de cooperación de mutuo beneficio (ASEAN, 2016a). Los acercamientos entre ASEAN y la RPC se han concretado en el plano económico, en la materia de intercambio de importaciones y exportaciones (figura 6) donde han mostrado un crecimiento

1 ASEAN +3 está compuesto por los diez países que forman parte de ASEAN, más China, Japón y Corea del Sur. 
sostenido para el periodo de 1994 al 2014, únicamente para el periodo 2008 se mostró una disminución de la tendencia, coincidente con la crisis financiera originada en los Estados Unidos de América (Navas, 2008).

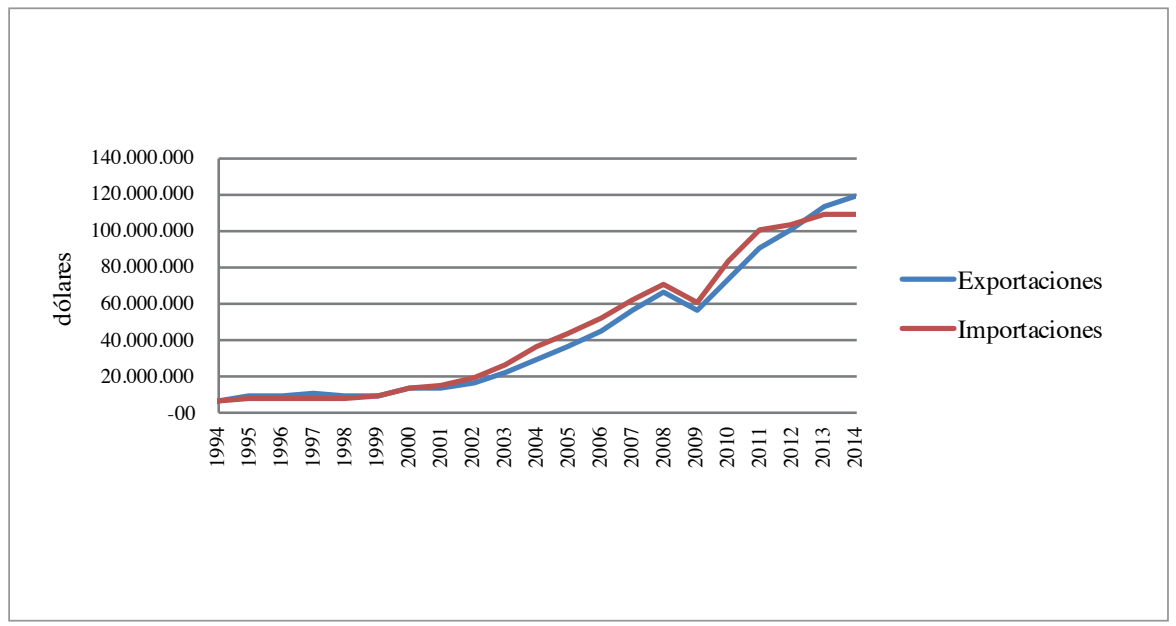

Figura 6. Exportaciones e importaciones de China con Asia 1994-2014 (A base de 10.000 dólares). Elaboración propia a partir de datos de la Oficina de Estadísticas Nacionales de China.

Para el año 2013 ASEAN y la RPC establecen, de manera conjunta, once áreas prioritarias de trabajo para la cooperación, a saber: agricultura, informaciones y comunicaciones tecnológicas, desarrollo del recurso humano, desarrollo de la cuenca Mekong, inversiones, energía, transporte, cultura, salud pública, turismo y ambiente (ASEAN, 2016a). Asimismo, un elemento que se debe destacar desde la perspectiva de las políticas pública es el hecho de que la declaración trajo consigo el desarrollo de dos planes de acción de aplicación conjunta para los periodos 2010-2015 y 2016-2020, este último aprobado en agosto del 2015 (ASEAN, 2016a). 


\section{REVISTA90.1}

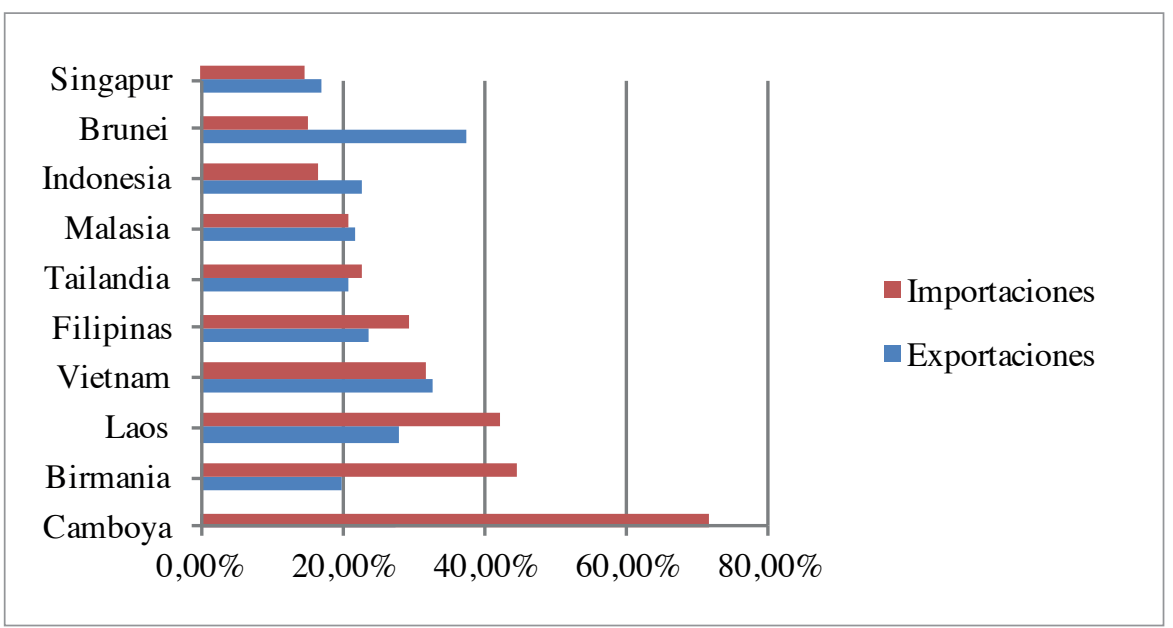

Figura 7. Crecimiento promedio de las exportaciones e importaciones de China con países de la ASEAN, 1994-2014. Elaboración propia a partir de datos de la Oficina de Estadísticas Nacionales de China.

Además, otro elemento que se debe considerar es el proceso de inversión extrajera directa que ha desarrollado la RPC sobre los países de la ASEAN, si bien esta no ha sido equitativa para todos los países, ha sido constante a través de los años (figura 8), y se ha intensificado a partir de la entrada en vigencia del tratado de libre comercio en el año 2005.

\section{Inversión}

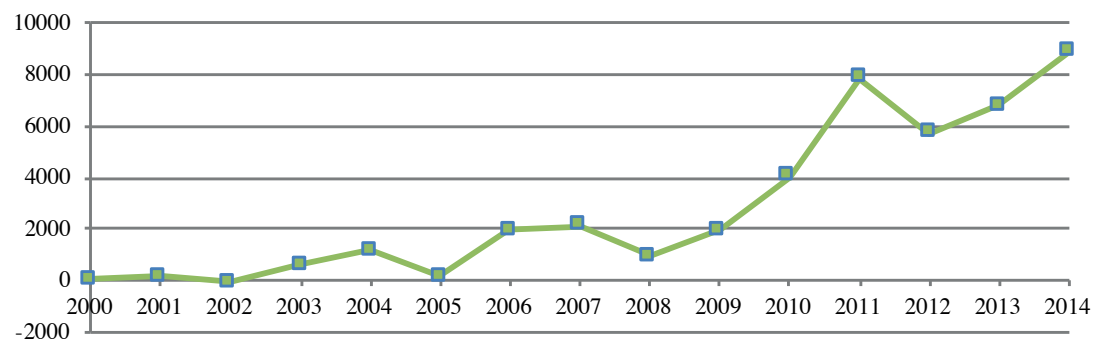

Figura 8. Inversión extranjera directa de China para la ASEAN, 2000-2014 (En millones de dólares). Elaboración propia a partir de datos de Asean. 
Al considerar el volumen de intercambio (ver anexo 1 y 2) y las tasas de crecimiento reportados en la figura 7 , se pueden dividir en tres grupos: si se consideran las importaciones que realiza la RPC, los de un alto crecimiento superiores al $40 \%$ de los países miembros de la ASEAN (Camboya, Birmania y Laos); los que tienen crecimiento moderado superiores al $20 \%$ y menores de $40 \%$ (Vietnam, Filipinas, Tailandia y Malasia), y los menores de 20\% (Indonesia, Brunei y Singapur). No obstante, se debe señalar que estas tasas de crecimiento facilitan la creación de condiciones para el fortalecimiento de la región.

\section{Conclusiones}

Los datos revisados muestran que la ASEAN parece no haber propiciado una fuerte integración económica entre sus países miembros desde su origen, a pesar de haber adoptado mediadas en relación con este tema. La explicación a este fenómeno puede residir en que la organización nace con una orientación eminentemente política, por lo que no se concentra en la integración económica sino hasta finales de la década de 1980; como un intento de hacer frente a acuerdos económicos y comerciales que se estaban gestando en diversas partes del mundo (por ejemplo: el NAFTA), y los cuales se visualizaban como una amenaza para la economía de la región (Hwee, 2007).

Sin embargo, todo parece apuntar que el proceso llevado a cabo tanto a lo interno de la ASEAN, como en la relación de esta con la RPC, responde a un proceso de integración regional, ya que este es promovido por las autoridades políticas de las naciones involucradas, a pesar de que su objetivo primario actual se encuentre en lograr la integración económica de la región.

Además, se debe anotar que el proceso de integración llevado a cabo responde tanto a un modelo positivo como negativo. En el caso de la relación de China con ASEAN, este es un proceso negativo, ya que va dirigido a la eliminación de restricciones arancelarias y comerciales, con el propósito de instaurar un área de libre comercio común.

Por otra parte, la relación entre los países de la ASEAN muestra un proceso de integración tanto negativo como positivo, en el primer caso por la negociación de tratados comerciales entre sus miembros; en el segundo, la propia formación de ASEAN responde a la creación de una organización supranacional, por medio de la cual los países que la integran pueden coordinar su accionar político en procura de obtener una mejor posición en el sistema internacional.

No obstante, a pesar de tener un impacto limitado en la integración económica de la región, diversas autorías reconocen la importancia de ASEAN en lo que 
respecta al plano de la integración política y a la formación de una identidad como región (Rubiolo, 2006 y Hwee, 2007; Higueras, 2005). Lo anterior le ha permitido funcionar como un mecanismo para que los países miembros de la organización puedan coordinar la construcción de intereses comunes desde una perspectiva constructivista:

Hasta aquí puede verse que la misma naturaleza de la ASEAN está constituida por elementos esenciales de la teoría constructivista: la posibilidad de construir intereses que son intrínsecos a las interacciones porque son modelados por una estructura intersubjetiva que se constituye a partir del conocimiento mutuo generado en las interacciones. (Rubiolo, 2006, p. 45)

La participación económica de la RPC a partir de la vigencia del tratado de libre comercio con los países de la ASEAN se ha hecho manifiesta no solamente en el campo del intercambio de productos y servicios por medio de las exportaciones e importaciones, sino que además ha permitido tener una incidencia positiva en los ingresos per cápita de los países, así como en la disminución de la pobreza, no obstante, el gran desafío se encuentra en la disminución de la desigualdad del ingreso, la cual solamente en dos países se ha logrado tener una reversión a la tendencia de aumento.

Asimismo, la presencia de la RPC dentro de las cumbres de ASEAN y los acercamientos que ha ido desarrollando permiten establecer los cimientos para un proceso de integración de la región, deben ser entendidos como vínculos frágiles, debido a la disputa del Mar Meridional de China y al poco avance que se han tenido en otras áreas más allá del auge de las actividades económicas propias del tratado de libre comercio. 


\section{Referencias}

ASEAN. (2015). Selected basic ASEAN indicators. Recuperado de http://www. asean.org/?static post $=$ selected-key-indicators-2

ASEAN. (2016a). Overview of ASEAN-China Dialogue Relations. Recuperado de: http://www.asean.org/?static_post=overview-asean-china-dialogue-relations

ASEAN. (2016b). Asean Members State. Recuperado de http://www.asean.org/ asean/asean-member-states/

ASEAN. (2016c). List of Instruments. Recuperado de http://agreement.asean.org/

Alzugaray Treto, C. (2009). La construcción de regiones: Un acercamiento teórico inicial para su aplicación comparada a América Latina y el Caribe. Documento de trabajo N. . $^{\circ} 20$ Centro de Estudios y Programas Internacionales. Recuperado de http://interamericanos.itam.mx/working papers/20ALZUGARAY.pdf

Banco Mundial. (2014). Poverty \& Equity. Recuperado de http://povertydata.worldbank.org/poverty/region/SAS

Balassa, B. (1980). Teoría de la integración económica. Uteha. México. D.F. Parte III. Integración y Política Económica.

Delage, F. (2003). La política exterior china en la era de la globalización. Revista CIDOB d'Afers Internacionals, 63, 67.81.

EFE. (01 de enero de 2010). Entra en vigor el TLC China-ASEAN. El Universal Recuperado de http://archivo.eluniversal.com.mx/notas/648982.html

Guerrero, D. y Mendieta, R. (2013). La Asociación de Naciones del Sudeste Asiático. Revista Electrónica de Investigación en Ciencias Económicas 1(2),13-31.

Hernández, M. (2008). Recesiones mundiales. El País. Recuperado de http:// www.elmundo.es/especiales/2008/10/economia/crisis2008/crisishistoricas/index.html

Higueras, G. (2005). ASEAN, la fuerza integradora de Asia. Anuario Asia Pacifico (55-65). Recuperado de http://www.anuarioasiapacifico.es/ pdf/2005/008Georgina_Higueras.pdf

Hurrell, A. (1995). Comparación entre Europa y América: ¿Qué clase de problemas? ¿Qué clase de teorías? En A. Borja, G. González y B. R.J. Stevenson (Eds.), Regionalismo y poder en América: Los límites del neorrealismo. México DF: Centro de Investigación y Docencia Económica (CIDE) y Grupo Editorial Miguel Ángel Porrúa. 
Hwee, Y. L. (2007). XL Aniversario de la ASEAN: Logros y retos principales. Anuario Asia Pacifico (pp. 111-118). Recuperado de http://www.anuarioasiapacifico.es/pdf/2007/Politica1.pdf

Malamud, A. (2011). Conceptos, teorías y debates sobre la integración regional. Norteamérica, 6(2), 219-249.

Moseley, C. (Ed.). (2007). Encyclopedia of the world's endangered languages. New York: Routledge.

Navas, J. (2008). Qué está pasando. El País. Recuperado de http://www.elmundo. es/especiales/2008/10/economia/crisis2008/queestapasando/index.html

Plaza Cerezo, S. (1995). La ASEAN: Proyecto de integración económica en el Sudeste Asiático. Recuperado de http://revistas.bancomext.gob.mx/rce/magazi$\underline{\text { nes/327/3/RCE3.pdf }}$

Plaza Cerezo, S. (1995) "La ASEAN: proyecto de integración económica en el Sudeste Asiático". Revista de Comercio Exterior. p. 840-849. Recuperado de: http://revistas.bancomext.gob.mx/rce/magazines/327/3/RCE3.pdf

Quiroga, C. (2009). China, 30 años de crecimiento económico. Anuario Jurídico y Económico Escurialense, 42, 463-480.

Rubiolo, F. M. (2006). Asociación de Naciones del Sudeste Asiático: Construcción de una identidad común. Centro Argentino de Estudios Internacionales. Recuperado de http://www.caei.com.ar/sites/default/files/21_2.pdf

Vilaro, R. (3 de febrero de 1985) Clima de crisis en Filipinas ante el juicio por el asesinato de Benigno Aquino. El País. Recuperado de http://elpais.com/dia$\underline{\text { rio/1985/02/03/internacional/476233218_850215.html }}$

Wilhelmy, M. (2000). El proceso de reformas en China y su política exterior Revista de Estudios Públicos, 78, 243-275. 


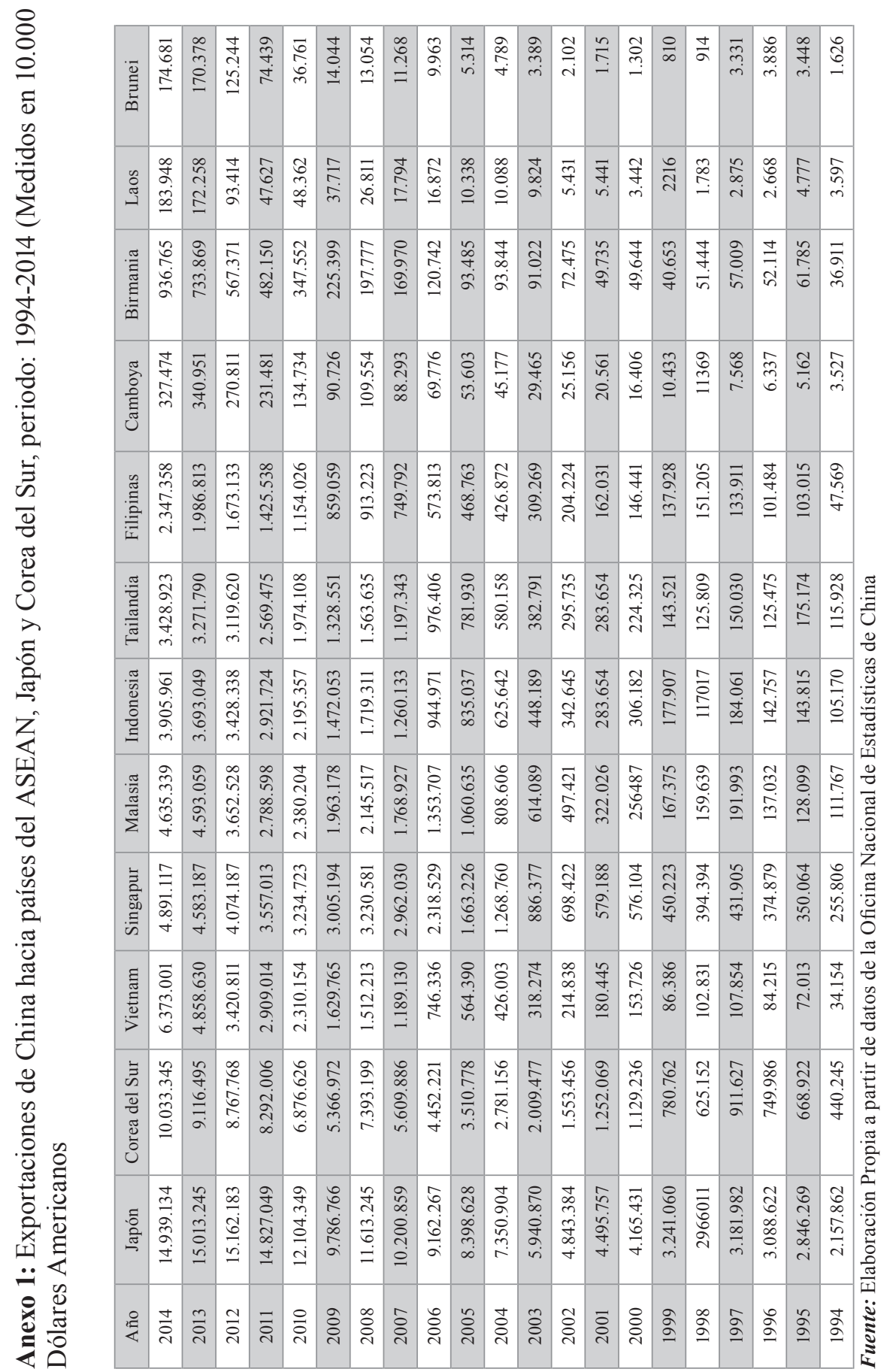


REVISTA 901

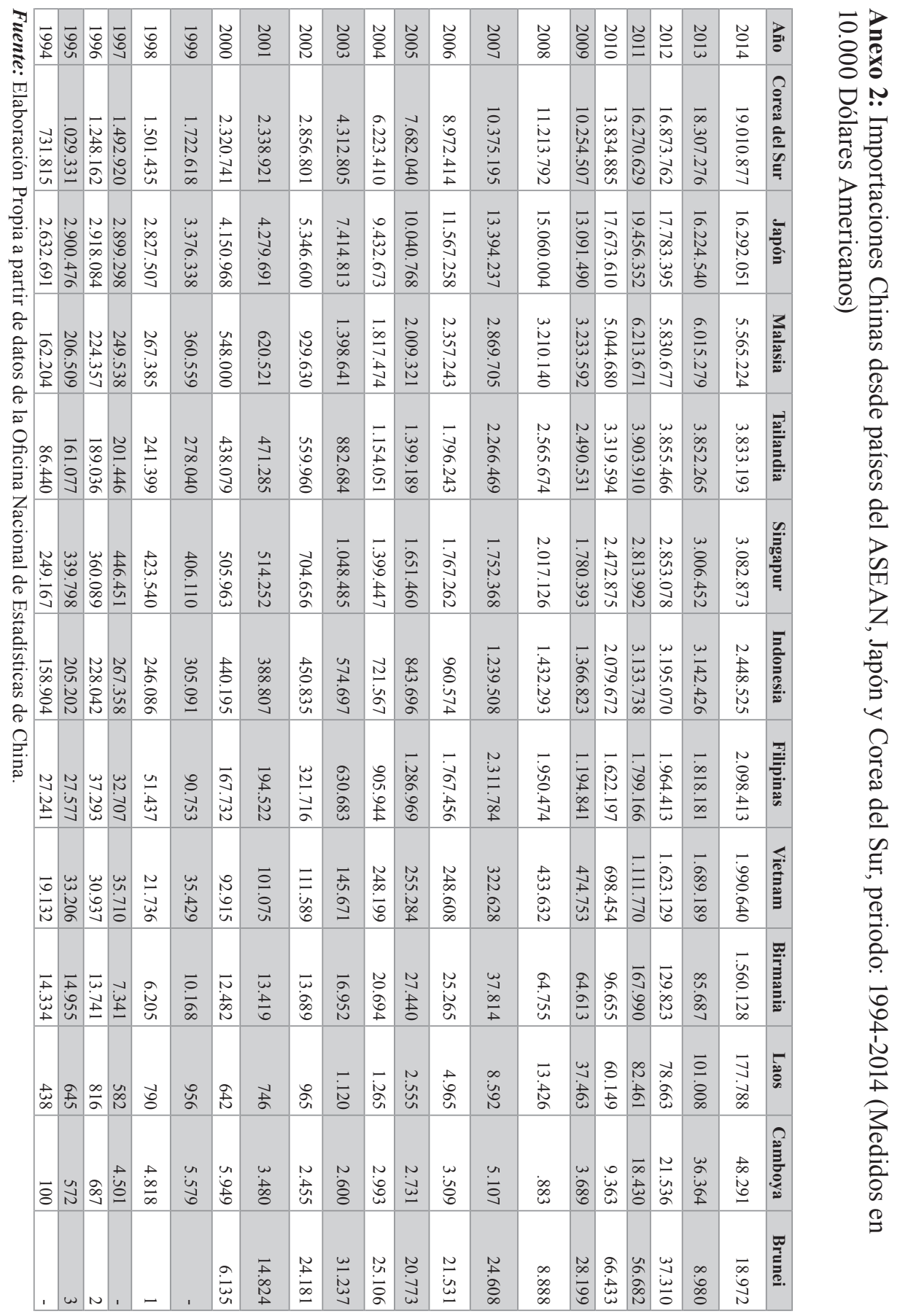

